\title{
Summarizing of Nusselt numbers and Euler numbers in depending of Reynolds number for the compact tube bundle of small diameter tubes by experimental and numerical methods of researches
}

\author{
Valery Gorobets ${ }^{1}$, Yurii Bohdan ${ }^{2,}$, Viktor Trokhaniak ${ }^{1}$, Ievgen Antypov ${ }^{1}$ and Mykola Masiuk ${ }^{1}$ \\ ${ }^{1}$ Heat and Power Engineering Department, Education and Research Institute of Energetics, Automation and Energy Efficiency, National \\ University of Life and Environmental Sciences of Ukraine, Heroyiv Oborony st., 15, Kyiv, 03041, Ukraine \\ ${ }^{2}$ Vessel's Power Plant Operation Department, Marine Engineering Faculty, Kherson State Maritime Academy, Ushakova avenue, 20, \\ Kherson, 73000, Ukraine
}

\begin{abstract}
The work reports on the experimental research on the determination of the number of Nusselt concerning the compact bundle of small diameter smooth tubes. Having an inline arrangement, it lacks the gaps between adjacent tubes of longitudinal rows. In comparison to the traditional inline arrangement, this type of bundle is noticed to have significant advantages such as an increased coefficient of heat transfer and reduced aerodynamic resistance of the tube bundle. At the same time, the use of the compact bundle of small diameter smooth tubes leads to the beneficial reduction of the size and mass of heat exchangers of the shell-and-tubes type. Several series of experimental investigations upon the aforementioned kind of bundle in open circuit section type wind tunnel of subsonic speeds applying various hydrodynamic flow conditions are ran. As a result of these investigations, the correlations and definite dependences of the Nusselt numbers $\mathrm{Nu}$ and Euler numbers Eu on the Reynolds number Re of tube bundle were revealed.
\end{abstract}

\section{Introduction}

There is a tendency in the world-wide heat transfer practice for having a general approach to tube bundles recognition as being the main part of shell-and-tube heat exchangers [1-5]. Due to the definite ease of preparation, they are known to be broadly used in significant number of industrial equipment. Even though plate heat exchangers are considered often to be compact and economic issues, they are unable to compete with shelland-tube ones being more advanced in reliability and work duration, especially if we are taking into account the flows in the heat exchanger applied under a different kind of pressure.

One of the effective directions for creating gas-liquid shell-and-tube heat exchangers of high energy efficiency and low-pressure drop is the use of inline tube bundles of increased compactness, being realized by using smooth tubes of small diameter and their compact arrangement in tube bundles [6].

Zukauskas et al. [6], Pronin [7], Anisin [8], Aiba et al. [9], Achenbach [10] performed certain ranges of tests described in their researches concerning the flow and heat transfer of cross-flow tube bundles. It must be paid attention to the fact that an enormous quantity of manuscripts, being suggested by the literature search [11] since 1996, can generally be described as a numeric one. This change might be mostly explained by the huge computer power enhancement which has been constantly occurring since the past decades. Undoubtedly, experimental investigation combined with numerical simulation is reviewed to be the most profitable and advantageous way of data analyzing and summarizing the results of hydrodynamic and heat transfer processes occurring in tube bundles.

Nevertheless, regarding all existing thermal, aerodynamic disquisitions of the correlation of crossflow of small diameter tube bundles and the absence of clearances between adjacent tubes of longitudinal rows, there is a formidable necessity in proper subsequent studies.

The research purpose strategy of conducted investigation can be defined as the analysis and summary providing of the data relating to the average heat transfer characteristics, Nusselt and Euler numbers for compact tube bundle of small diameter smooth tubes with the inline arrangement and minimum longitudinal relative step equal to unity in cross-flow. The results of the determination of Nusselt number for a compact bundle of smooth tubes of small diameter compared with numerical modeling results and conventional heat transfer correlations were obtained through the practical approach of investigation.

\footnotetext{
* Corresponding author: bohdanyurii09@gmail.com
} 


\section{Research description}

\subsection{Experimental plant}

It must be mentioned that the study of heat transfer, aerodynamic resistance and the laws of flowing the gas stream of tube bundles is conventionally performed using wind tunnel $[6,12,13]$. As said previously, we had particularly used the open circuit section type wind tunnel of subsonic speeds. Complete information will be provided below and several basic concepts will be introduced (Figure 1).

The installation we have been using comprises of sections: forming the flow passage (manifold (1), Witoshinsky nozzle (3), stabilizing section (5), test section (6), calming section (8), inserted-joint pipe (9)) and one axial fan (10) the capacity of $11000 \mathrm{~m}^{3} / \mathrm{h}$ and the pressure of $370 \mathrm{~Pa}$, which is driven by a $2.2 \mathrm{~kW}$ three-phase induction motor.

The wind tunnel is generally known to be functioning on the principle of the suction channel with dimensions of the test section of $300 \mathrm{~mm}$ by $300 \mathrm{~mm}$.

The air flow rate can be successfully adjusted by the current frequency converter whose purpose is to be involved in the regulation process of the speed of the motor rotor and, as a result, the fan impeller speed causing the air flow changes.

Accordingly, the wind tunnel is equipped with several measuring equipment to gauge the process parameters of heat transfer and hydrodynamics.

In particular, we have been using the following plants:

1) Thermocouple thermometers Hti HT-9815,

2) Chrome-Copel thermocouples for temperature

measurement of the heat transfer surface on the gas side,

3) Heat-loss anemometer "AM-70",

4) Pitot-Prandtl (tube) gage,

5) Micromanometer "MMH-2400(5)" accuracy Class1.0,

6) Differential pressure flow meter "Testo 510".

Investigated tube bundle consist of smooth tubes with diameter and thickness $-d \times \delta=0.010 \times 0.001 \mathrm{~m}$, the tube material is steel, the equivalent diameter of the channel between rows of tubes is $D_{\text {chan.eq }}=0.00967 \mathrm{~m}$, length of tubes is $l=0.300 \mathrm{~m}$, equivalent diameter of casing is $D_{\text {cas.eq }}=0.300 \mathrm{~m}$, tube rows number is 19 with 4 tubes in each row.

Zukauskas and Ulinskas [6] pointed out to the highly congenial usage of 4 rows plant for the heat transfer to entirely work out in a free tube bundle. One part of it represents a calorific type with the electrical heater inside. It must be referred that the voltage at the terminals of the heater is being set with the help of a laboratory transformer and the current is being measured by an ammeter. Before the gauging process, the duration span of 60 minutes for the calorimeter tube heating was observed. The heat capacity of the electrical heater was considered to be all way constant end equivalent to $26 \mathrm{~W}$ while the range of air velocity during the experiments varied from 0 to $7.0 \mathrm{~m} / \mathrm{s}$. The last issue was done by fan and frequency converter which are being used for the required air speed settings. This process has resulted in

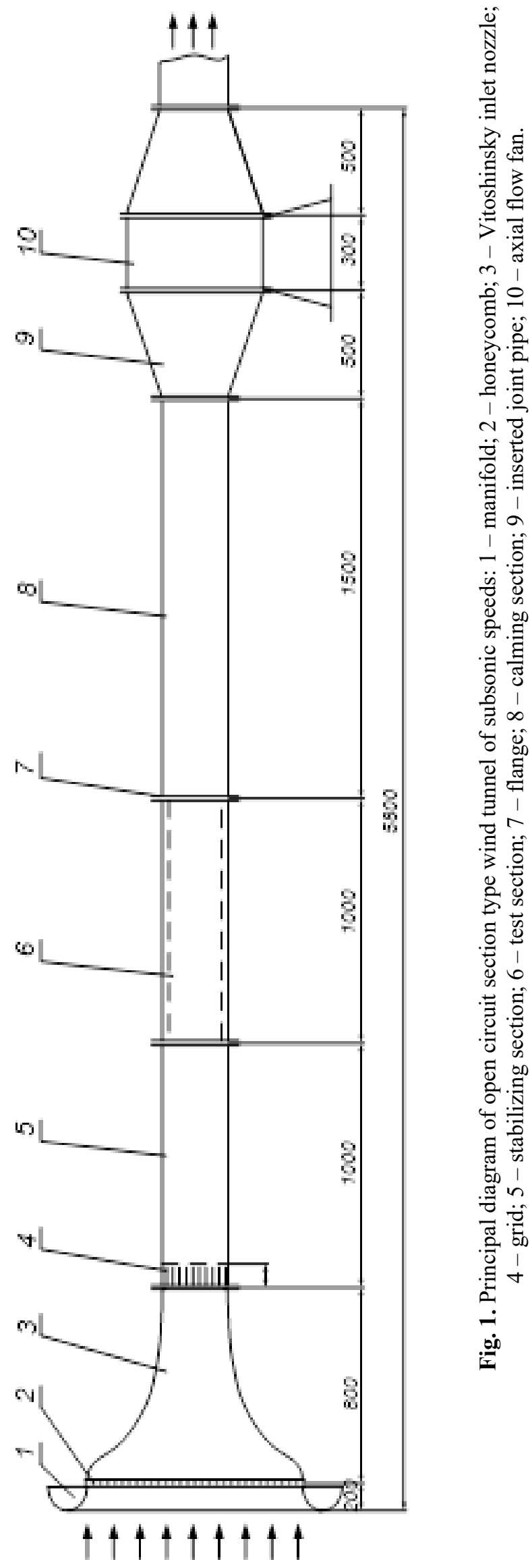


the changes in air velocity leading to the variation of the range of values of the Reynolds Numbers Re from 0 to 5000 .

For the aim of the determination of temperature on the surface of the calorimetric tube along all its length 3 chromel-copel thermocouples are inserted. Therefore, the arrangement of them is detailed as follows: one part is in the middle and the others are at a distance of $15 \mathrm{~mm}$ from the tube ends.

During the main experiment performance the subsequent characteristics were taken: air flow, air temperature at the entrance to the test section and the mass-average temperature at the exit from it, static and total inlet pressure, total pressure at the outlet of the tube bundle, temperature of the calorimetric tube wall, the drop in static pressure over the whole length of the test section.

Specific attention must be paid to the fact that the numerical modelling of aerodrodynamics and heat transfer processes are carried out for the tube bundle. These calculations are recognized to be efficiently beneficial in obtaining of the fields of velocities, temperatures and pressures, and as well as acquiring of Nusselt numbers and Euler ones depending on Reynold numbers.

In particularly, the geometry of the investigated tube bundle with the small diameter tubes is depicted in Figure 2 possessing the following characteristics: values of transversal and longitudinal step of tubes $S_{a} \times S_{b}=$ $0.015 \times 0.010 \mathrm{~m}$, the diameter of tubes $d=0.010 \mathrm{~m}$, number of tubes in row $i=4$, the tube bundle consist of $j=19$ row, and the common number of tubes in the bundle makes $z=76$.

\subsection{Numerical modelling}

The emphasis must be placed on the implementation of numerical modeling of processes of heat transfer and hydrodynamics in the tube bundle utilizing ANSYS Fluent software. Mathematical two-dimensional model of heat- and mass transfer processes is reported to comprise a system of Navier-Stokes equations, equation of energy transfer for convective flows [14] and the standard k- $\varepsilon$ model of turbulence [15].

Equations of convective transfer of mass and energy are introduced as follows:

$$
\left.\begin{array}{c}
\frac{\partial \rho w_{x}}{\partial \tau}+w_{x} \frac{\partial \rho w_{x}}{\partial x}+w_{y} \frac{\partial \rho w_{x}}{\partial y}=-\frac{\partial p}{\partial x}+\frac{\partial}{\partial x}\left(\mu_{e f} \frac{\partial w_{x}}{\partial x}\right)+\frac{\partial}{\partial y}\left(\mu_{e f} \frac{\partial w_{x}}{\partial y}\right) \\
\frac{\partial \rho w_{y}}{\partial \tau}+w_{x} \frac{\partial \rho w_{y}}{\partial x}+w_{y} \frac{\partial \rho w_{y}}{\partial y}=-\frac{\partial p}{\partial y}+\frac{\partial}{\partial x}\left(\mu_{e f} \frac{\partial w_{y}}{\partial x}\right)+\frac{\partial}{\partial y}\left(\mu_{e f} \frac{\partial w_{y}}{\partial y}\right)
\end{array}\right\}
$$

Therewith, the two-parameter standard $k$ - $\varepsilon$ model consisting of two differential equations of kinetic energy transfer and velocity of dissipation is provided for the modelling of turbulent flow.

$$
\begin{aligned}
& \frac{\partial \rho k}{\partial \tau}+w_{x} \frac{\partial \rho k}{\partial x}+w_{y} \frac{\partial \rho k}{\partial y}=\frac{\partial}{\partial x}\left(\frac{\mu_{e f}}{\sigma_{k}} \frac{\partial k}{\partial x}\right)+\frac{\partial}{\partial y}\left(\frac{\mu_{e f}}{\sigma_{k}} \frac{\partial k}{\partial y}\right)+G_{k}-\rho \varepsilon, \\
& \frac{\partial \rho \varepsilon}{\partial \tau}+w_{x} \frac{\partial \rho \varepsilon}{\partial x}+w_{y} \frac{\partial \rho \varepsilon}{\partial y}=\frac{\partial}{\partial x}\left(\frac{\mu_{e f}}{\sigma_{\varepsilon}} \frac{\partial \varepsilon}{\partial x}\right)+\frac{\partial}{\partial y}\left(\frac{\mu_{e f}}{\sigma_{\varepsilon}} \frac{\partial \varepsilon}{\partial y}\right)+c_{\varepsilon 1} G_{k} \frac{\varepsilon}{k}-c_{\varepsilon 2} \rho \frac{\varepsilon^{2}}{k}, \\
& \text { where } \mu_{e f}=\mu+\mu_{t}, \lambda_{e f}=\lambda+\lambda_{t}, \mu_{t}=\frac{c_{\mu} \rho k^{2}}{\varepsilon}, G_{k}=\mu+\frac{\partial w_{x}}{\partial x_{i}}\left(\frac{\partial w_{j}}{\partial x_{i}}+\frac{\partial w_{i}}{\partial x_{j}}\right) \\
& c_{\mu}=0.09, c_{\varepsilon 1}=1.44, c_{\varepsilon 2}=1.92, \sigma_{k}=1, \sigma_{\varepsilon}=1.3 .
\end{aligned}
$$

The next ensuing boundary conditions used for modelling can be defined as:

$w_{i}(\tau=0)=0, w_{i}(x=0)=w_{i n}, w_{i}\left(x_{i}=x_{w}\right)=0,\left.t\right|_{s}=\left.t_{w}\right|_{s}$

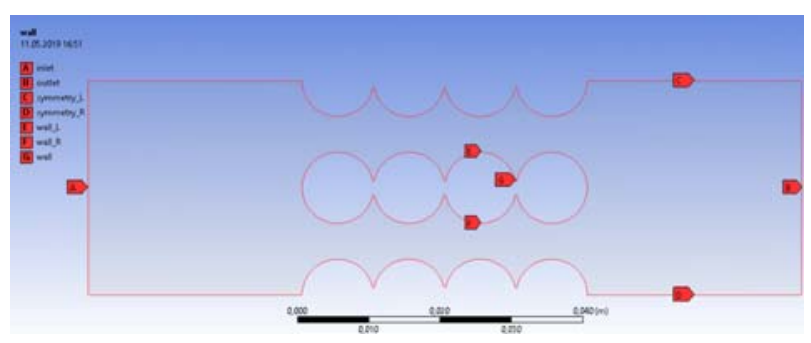

Fig. 2. Geometry of tube bundle arrangement inside test section.

The numerical calculations in the investigated tube bundle are carried out with the Reynolds number $\mathrm{Re}=$ 4946. Besides, air with a temperature at the inlet of $16{ }^{\circ} \mathrm{C}$ is flowing in the channels of the tube bundle. It is used as a heat carrier. The temperature of the wall of the calorific tube was assumed to be constant.

The finite element method to be assuredly auspicious for being used in the numerical calculation of the problems of hydrodynamics and heat transfer is used. As for mesh construction, it was carried out in the mesh generator ANSYS Meshing on the basis of the Workbench platform. For its construction, the local mesh control is made use of. The design of a boundary layer operated by the method of "Total Thickness" (the thickness of the first layer is determined as being $5 \cdot 10^{-5} \mathrm{~m}$ with the number of 6 layers) (Figure 3 ) is predominantly defined to represent the construction of a quadrilateral dominant mesh (Figure 4).

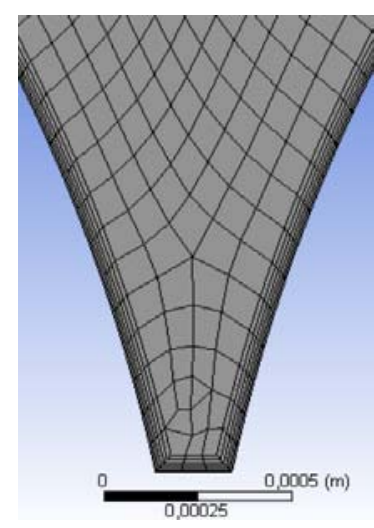

Fig. 3. Design of a boundary layer by the method of "Total Thickness". 


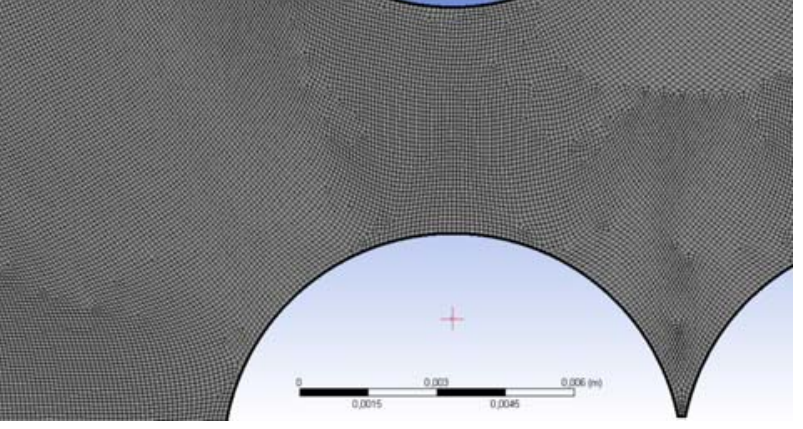

Fig. 4. Construction of a quadrilateral dominant mesh.

To be more precise, the following features are observed: the mesh orthogonal quality is equal to 0.55 , the minimum size of the element corresponds to $1 \cdot 10^{-6} \mathrm{~m}$, the maximum dimension of the face is considered to be $1 \cdot 10^{-4} \mathrm{~m}$ and the number of elements is calculated as being about 280 thousand.

\section{Results and discussions}

The distribution of the velocity vectors in the tube bundle is depicted in Figure 5.

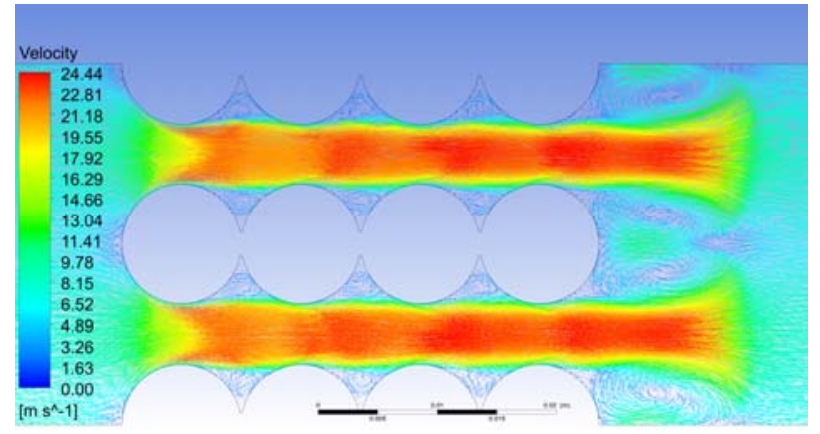

Fig. 5. Velocity vector in the channels of tube bundle, $\mathrm{m} / \mathrm{s}(\operatorname{Re}=4946)$

As it is seen from the mentioned above Figure 5 the value of the average velocity of air in the narrowest cross-section of the channel reaches $22 \pm 2 \mathrm{~m} / \mathrm{s}$.

In the following Figure 6 the illustration of the temperature distribution in the channels with the air temperature value both at the inlet and outlet equal $16^{\circ} \mathrm{C}$ is proposed. Thus, it tends to signify the complete removal of heat from the calorimetric tube at $\mathrm{Re}=4946$.

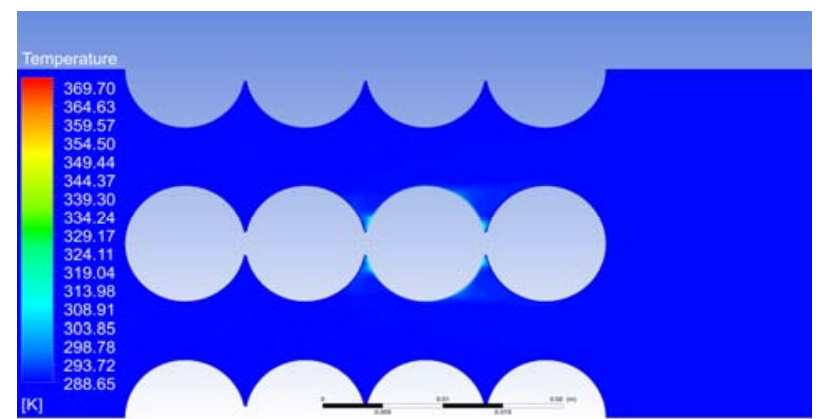

Fig. 6. Change of temperature in the channels of tube bundle, ${ }^{\circ} \mathrm{C}(\mathrm{Re}=4946)$

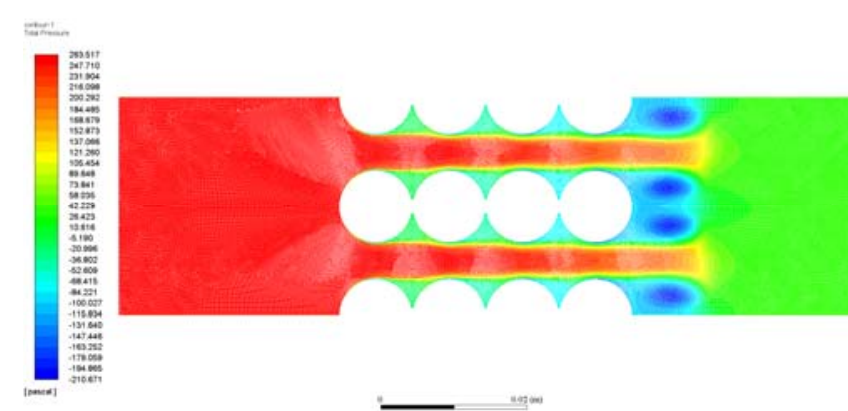

Fig. 7. Change of pressure in the channels of tube bundle, $\mathrm{Pa}(\mathrm{Re}=4946)$.

Figure 7 depicts the obvious pressure change in the flow of air passing along the channels of the tube bundle.

The dependence of the mean of Nusselt on the Reynolds number can be presented through the following form of power function:

$$
\mathrm{Nu}=\mathrm{A} \cdot \operatorname{Re}^{\mathrm{n}} \operatorname{Pr}^{\mathrm{r}}
$$

where $\mathrm{A}, \mathrm{n}$ and $\mathrm{r}$ are experimental constants.

Concerning gases, it must be emphasized that the Prandtl number practically is not changed with the temperature. So, we assume we can easily avoid its taking into account in formula 5.

Therefore, all experimental data is performed through the algebraic generalization in the form of a similarity equation:

$$
\mathrm{Eu}=\mathrm{B} \cdot \mathrm{Re}^{\mathrm{m}},
$$

where $\mathrm{B}$ and $\mathrm{m}$ are experimental constants.

The investigation results of the flow and heat transfer in the tube bundle with the absence of gaps between adjacent tubes of longitudinal rows were easily verified by means of trend comparing of obtained experimental data (the wind tunnel) with the output of the numerical simulation, well-known experiments and modeling. Further to it, they are proposed to be demonstrably illustrated in the form of graphical dependences in Figures 8, 9 for Reynolds numbers in the range $\mathrm{Re}=0 \div$ 6000 and Prandtl number $\operatorname{Pr}=0.73$.

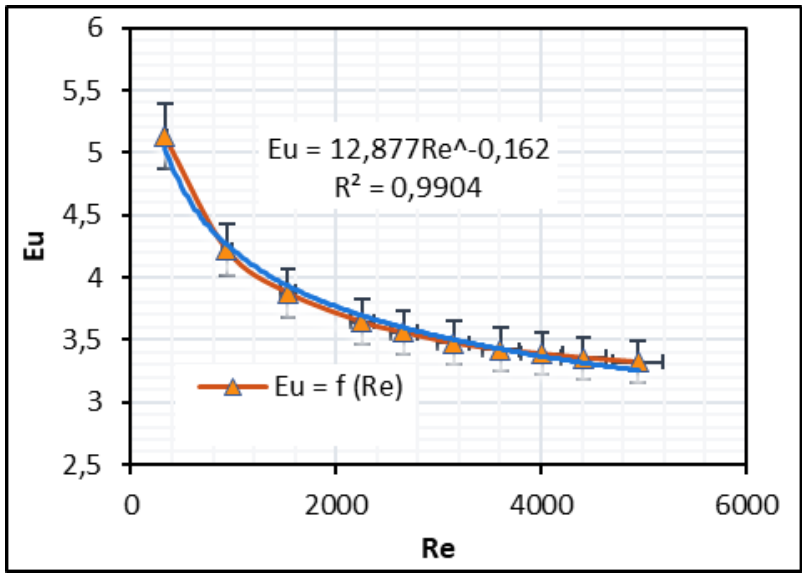

Fig. 8. Dependence of the Euler number Eu of air flow on Reynolds number Re: $\boldsymbol{\Delta}$ - results of numerical modeling for tube bundles installed on working section of wind tunnel. 


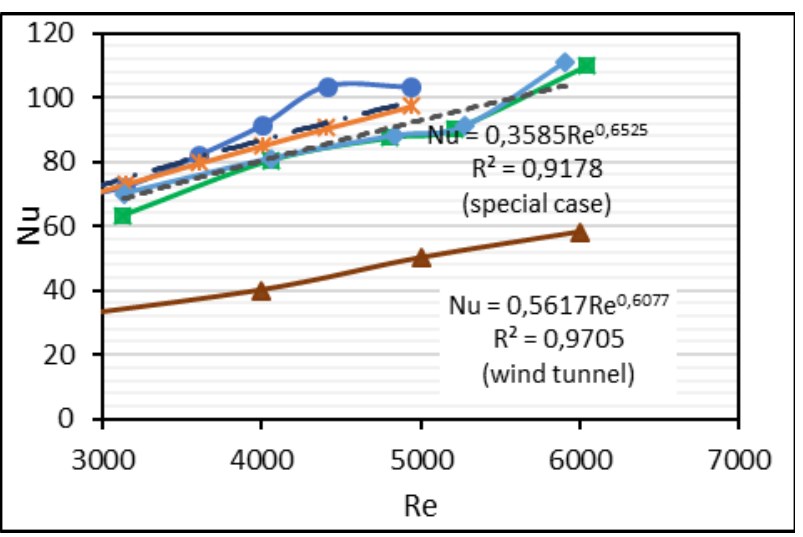

Fig. 9. Dependence of average Nusselt number $\bar{N} u$ on Reynolds number Re: $\bullet$ - experimental data for the compact tube bundle (wind tunnel) $\%$ - numerical results for the compact tube bundle (wind tunnel)

- experimental data for the compact tube bundle (special case [17]); $\boldsymbol{\Delta}$ - experimental data for the inline tube bundle $[6,16]$; - numerical results for the compact tube bundle (special case [17]).

So, Figure 9 depicts the experimentally determined correlation of Nusselt number being averaged over the surface $\bar{N} u$ with Reynolds number Re. Furthermore, it provides an obvious demonstration of the experimental dependence $\bar{N} u=f(\mathrm{Re})$ which was similar to the database for the inline tube bundle unto this day obtained by Zhukauskas, Belov and Kudryavtsev $[6,16]$. To be more precise, the correlation between the intensity of heat transfer for a compact bundle with small diameter tubes and the intensity transferred on the surface of the inline tube bundle validates the conclusion that with the same values of Reynold number there is an experimentally proved ratio $2: 1$ making it completely different.

\section{Conclusions}

1. Experimental and numerical researches, dependencies of the Nusselt number $\mathrm{Nu}$ and Euler number $\mathrm{Eu}$ on the Reynold number $\mathrm{Re}$ in the range of $0<\mathrm{Re}<5000$ of the investigated $19^{\text {th }}$-row tube bundle (four tubes in each row) were obtained.

2. The correlation approach is illustrated by calculating heat transfer and hydraulic resistance in the form of dependencies of the Nusselt number and Euler number on the Reynold number.

Under the range of practically-focused tests the dependencies were received in the form of power function and, what is notably significant, they provide the consent for the determination of the coefficients of heat transfer and hydraulic resistance in the development of tube type heat exchange equipment. To sum up, it must be underlined that the extracted information is completely able to illuminate the conclusion about having 1.7-2 times reducing of heat exchange size by using of a tube bundle with the absence of gaps between adjacent tubes of longitudinal rows.

\section{References}

1. G.F. Hewitt, Heat Exchanger Design Handbook (Begell House, New York, 2008)

2. D. Annaratone, Handbook for Heat Exchangers and Tube Banks design, (Springer, 2010)

3. K. Thulukkanam, Heat Exchanger Design Handbook (CRC Press, Taylor \& Francis Group, 2013)

4. J.E. Hesselgreaves, R. Law, D. Reay, Compact Heat Exchangers: Selection, Design and Operation Hesselgreaves (Butterworth-Heinemann, United Kingdom, 2016)

5. D. Taler, Numerical Modelling and Experimental Testing of Heat Exchangers (Springer, BerlinHeildelberg, 2019)

6. A. Zhukauskas, R. Ulinskas, Heat transfer of cross flow tube bundles (Mokslas, Vilnius, 1986)

7. V.A. Pronin, A.V. Dozortsev, V.E. Tyirin, Trans. of the 4rth Russian National Heat Exchange Conf., Moscow, 6, pp. 285-288 (2006)

8. A.A. Anisin, Increase of energy efficiency of smooth tube bundles and profile channels for gasliquid heat exchangers for power plants, Doctor of Engineering Science, Peter the Great SaintPetersburg Polytechnic University, 2009.

9. S. Aiba, T. Ota, H. Tsuchiba, Int. J. Heat Mass Tran., 23(3), pp. 311-319 (1980)

10. E. Achenbach, Int. J. Heat Mass Transf., 34(1), pp. 199-207 (1991)

11. J.M. Gorman, E.M. Sparrow, J. Ahn, Int. J. Heat Mass Transf., 132, pp. 837-847 (2019)

12. J.C. Lerner, Wind Tunnels and Experimental Fluid Dynamics Research, (InTech, 2011)

13. S. Okamoto, Wind Tunnels (InTech, 2011)

14. H. Schlichting, Boundary-Layer Theory, $7^{\text {th }}$ edition, (McGraw-Hill, New York, 1979)

15. ANSYS FLUENT Theory Guide. Release 14. ANSYS, Inc. Southpointe 275 Technology Drive Canonsburg, PA 15317, 2011

16. I.A. Belov, N.A. Kudryavtsev, Heat transfer and resistance of tube packs, (Energoatomizdat, Leningrad, 1987)

17. V. Gorobets, Yu. Bohdan, V. Trokhaniak, I. Antypov, Appl. Therm. Eng., 151, pp. 46-54 (2019) 